\title{
Multiple Congenital Anomalies and Developmental Delay in a Boy Associated With a De Novo 16p13.3 Deletion
}

\author{
Marc Nelson, ${ }^{1}$ Shane Quinonez, ${ }^{2}$ Todd Ackley, ${ }^{2}$ Ram K. lyer, ${ }^{2}$ and Jeffrey W. Innis ${ }^{2,3 *}$ \\ ${ }^{1}$ Department of Otolaryngology, University of Michigan, Ann Arbor, Michigan \\ ${ }^{2}$ Department of Pediatrics, University of Michigan, Ann Arbor, Michigan \\ ${ }^{3}$ Department of Human Genetics, The University of Michigan, Ann Arbor, Michigan
}

Received 29 July 2010; Accepted 25 October 2010

We describe a patient with multiple congenital anomalies including tracheobronchomalacia, CT-proven metopic craniosynostosis, glandular hypospadias and severe ventral chordee, torticollis, esotropia, strabismus, fifth finger clinodactyly, hallux valgus, and global developmental delay. Using high resolution chromosomal microarray analysis, we identified a de novo deletion of $555 \mathrm{~kb}$ on chromosome $16 \mathrm{p} 13.3,444 \mathrm{~kb}$ telomeric to the CREBBP gene and $623 \mathrm{~kb}$ centromeric of PKD1. Review of the literature revealed numerous reports of individuals with deletions involving adjacent regions including CREBBP, but only one overlapping with this isolated region of 16p13.3. Haploinsufficiency for one or more of the 25 candidate genes in the deleted genomic region may be responsible for these clinical features. No copy number variants (CNVs) span the entire region, but several small CNVs within the $555 \mathrm{~kb}$ genomic region reduce the likelihood for effects due to haploinsufficiency to 18 genes.

(c) 2011 Wiley-Liss, Inc.

Key words: 16p13.3; Rubinstein-Taybi; metopic craniosynostosis

\section{INTRODUCTION}

Numerous patients have been described with deletions involving chromosome 16p13 [Bartsch et al., 1999, 2006; Wójcik et al., 2010]. Some deletions include CREBBP, the cAMP responsive element binding protein gene, and give rise to Rubinstein-Taybi syndrome or a more severe form of RTS, which includes hypoplastic left heart, polysplenia, and an increased risk for death in infancy. The latter examples are typically larger deletions encompassing adjacent genes; however, the few patients described preclude confident assignment of genes associated with the severe phenotypes [Bartsch et al., 1999]. We report a child with a deletion of chromosome 16p13.3 by chromosomal microarray, confirmed by fluorescence in situ hybridization (FISH), which lies telomeric to CREBBP involving 25 genes. The clinical features of this child include multiple congenital anomalies distinct from Rubinstein-
How to Cite this Article:

Nelson M, Quinonez S, Ackley T, Iyer RK, Innis JW. 2011. Multiple congenital anomalies and developmental delay in a boy associated with a de novo 16p13.3 deletion. Am J Med Genet Part A 155:612-617.

Taybi syndrome, which may help to delineate the contribution of selected genes in the larger 16p13.3 deletion syndrome.

\section{CLINICAL REPORT}

The patient is a 6-year-old boy born at term. He was delivered by repeat elective cesarean at term after an uncomplicated pregnancy. There was no antenatal exposure to alcohol or other medications. Birth weight was $3750 \mathrm{~g}$. He did not require a stay in neonatal intensive care.

At 6.5 years, the patient was at the 60th centile for weight, 50th centile for height, and 50th centile for head circumference (Fig. 1). At 1 year of age, a head CT showed metopic synostosis, but there was no evidence to suggest increased intracranial pressure. Ophthalmologic examination was normal. Craniofacial anomalies noted early included mild trigonocephaly with prominence of the metopic suture and palpable ridge, widening of the nasal bridge and flattening in the right occipital area. The face demonstrated a triangular shape. The mouth was slightly small with mild retrognathia. The soft and hard palates were without clefting, yet the palate was highly arched. Ocular anomalies included bilateral esotropia, requiring surgical bilateral medial rectus recession. The

${ }^{\star}$ Correspondence to:

Jeffrey W. Innis, M.D., Ph.D., Departmentof Pediatrics, Division of Genetics, D5240 MPB, 1500 E. Medical Center Drive, Ann Arbor, MI 48109-5718. E-mail: innis@umich.edu

Published online 22 February 2011 in Wiley Online Library

(wileyonlinelibrary.com).

DOI 10.1002/ajmg.a.33808 


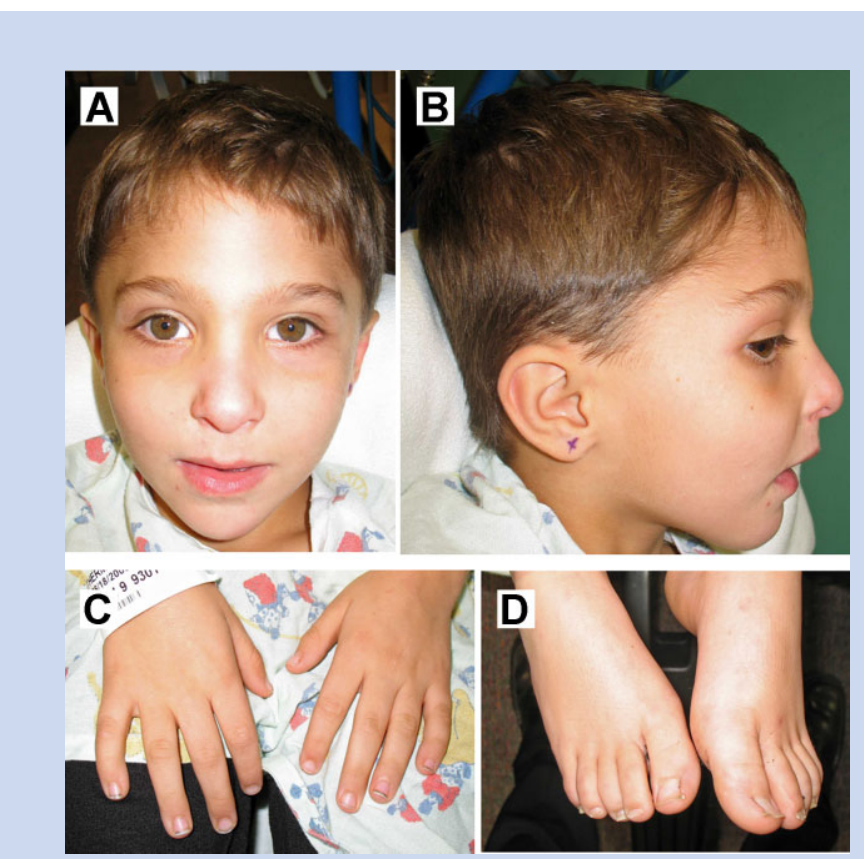

FIG. 1. Proband at 6.5 years of age. $(A, B)$ Note pointed chin, mild metopic prominence and slightly low set ears. Note the absence of typical facial features of RTS. [C,D] Clinodactyly of the fifth fingers, normal thumbs, normal width of the great toes, and hallux valgus. [Color figure can be viewed in the online issue, which is available at wileyonlinelibrary.com]

palpebral fissures were level, and inner and outer canthal distances were normal at the 50th and 80th centile, respectively. The auricles were slightly low set and posteriorly rotated. Skin exam was negative for pigmentary changes, rash or pallor.

The patient had a history of chronic serous otitis media, and underwent placement of tympanostomy tubes. Subsequent audiograms showed normal hearing bilaterally. He underwent adenotonsillectomy at 3 years of age for sleep-disordered breathing with $70-80 \%$ obstruction of the nasal airway due to enlarged adenoids. There was a history of tracheobronchomalacia, which required multiple hospitalizations and steroid therapy. There were also additional hospitalizations for episodes of recurrent croup and pneumonia. Fluoroscopic airway evaluation revealed mild subglottic stenosis. There were no cardiac arrhythmias or murmurs on exam. Extremities were notable for bilateral fifth finger clinodactyly, no syndactyly of the hands or feet, and bilateral pes planus. Muscle tone was increased especially in the lower extremities, with clonus in the ankles bilaterally. There was clasp-knife resistance to passive flexion at the hips and knees. The patient was hyperreflexic in the brachioradialis and patellar tendons. There was normal spine curvature, and the gait was normal. MRI of the head showed normal intracranial contents without any sign of increased pressure.

The patient had moderate developmental delays. He was able to roll to the prone position at 10 months of age, and began walking at 23 months. At a 20 month assessment, developmental scores ranged from 9 to 22 months. There was delay in cognitive skills, gross motor and speech skills, and difficulty with understanding and using language. Receptive language was greater than expressive language.
After enrollment in special education classes, the patient was noted to play preferentially with others rather than independently. At 41 months of age, the patient was capable of using 2-3 word sentences. There has been no regression of skills.

In addition to the procedures noted above, surgical history also included correction of hypospadias and severe ventral chordee at the corona at age 8 months. There was a history of torticollis, which was treated with physical therapy, and required no surgery. The patient has also been treated for gastroesophageal reflux disease, eczema, and attention deficit hyperactivity disorder.

Medical genetic evaluation of the family history disclosed no known history of consanguinity. Both parents as well as an older sister were asymptomatic. Workup included BAC-based and oligonucleotide based chromosomal microarray analyses (CMA; del16p13.3), karyotype (showing normal 46, XY), and FMR1 testing, which was normal.

\section{METHODS}

Informed consent was obtained for research approved by the Institutional Review Board for Human Subject Research at the University of Michigan. Chromosomal microarray analyses were conducted first at Signature Genomic Laboratories (BAC array) followed by the Michigan Medical Genetics Laboratories (MMGL) at the University of Michigan using an oligonucleotide-based array platform with whole genome coverage, the Agilent human genome G4411B 244K array platform (Agilent Technologies, Inc., Santa Clara, CA). The procedures for DNA digestion, labeling, and comparative genomic hybridization were as described in Agilent Oligonucleotide-Based Array CGH for Genomic DNA Analysis, Protocol version 4.0 June 2006 (Agilent Technologies, Inc.) with some modifications [Baldwin et al., 2008]. The fluorescent signals on the array slides were detected and scanned into image files using a GenePix 4200A scanner and GenePix-Pro 6.1 software (Axon Instruments/Molecular Devices Corp., Union City, CA). The array images were imported and converted for display by Agilent Feature Extraction 9.5 software. Data were analyzed by Agilent's CGH Analytics 3.5 software to determine copy number variation (CNV) between experimental DNA and a sex mismatched control DNA preparation. Numbering of the $244 \mathrm{~K}$ Agilent array results utilized the UCSC hg18 (Build 36.1, March 2006) assembly. Evaluation for CNV utilized the Database of Genomic Variants (http:// projects.tcag.ca/variation/) and the UCSC Genome Browser (http://genome.ucsc.edu/cgi-bin/hgGateway). FISH analysis for verification of the deletion used BAC probe CTD-3240C2 and a control chromosome 16 centromere probe and was performed using standard methods at Signature Genomic Laboratories (data not shown).

\section{RESULTS}

Chromosomal microarray analysis with a BAC array identified one copy loss of genomic DNA represented by three BAC clones, RP11-626F12, CTD-3240C2, and CTD-2131124. The deletion was confirmed by FISH with BAC probe CTD-3240C2 (not shown). FISH analysis of both parents using CTD-3240C2 was normal (not shown), indicating that the deletion in the proband occurred de 


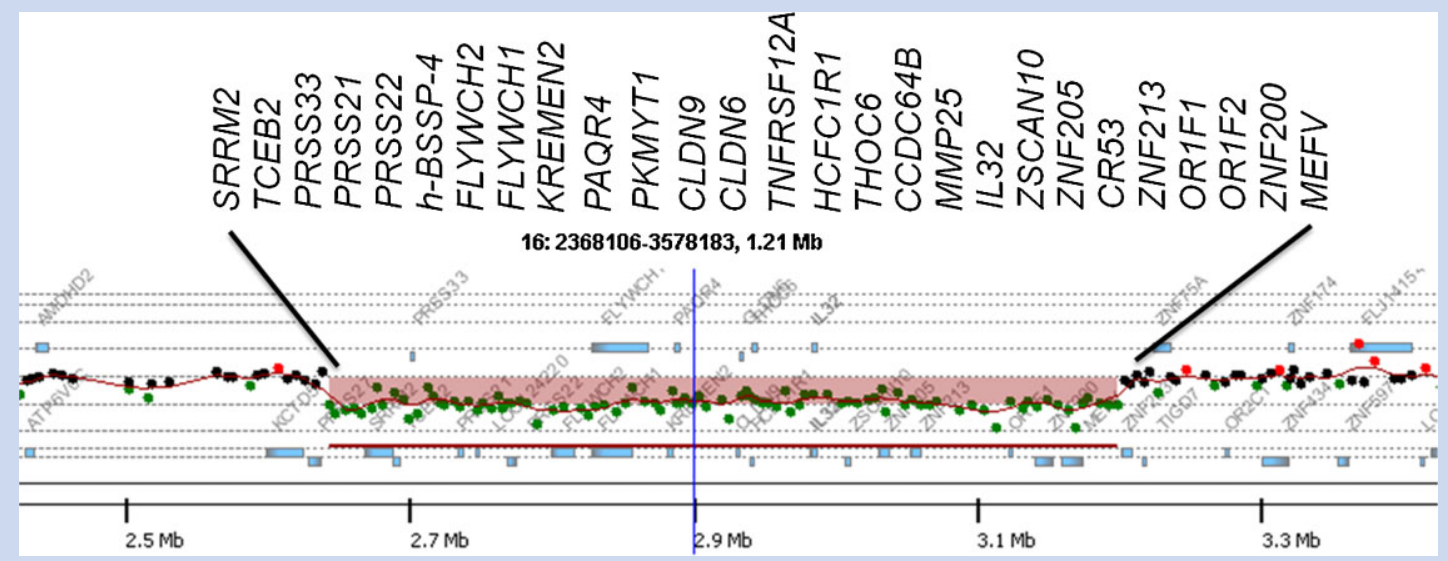

FIG. 2. Proband $244 \mathrm{~K}$ Agilent array CGH data. The $555 \mathrm{~kb}$ deletion in $16 \mathrm{p} 13.3$ is demarcated by the brown coloring. Coordinates shown below span $1.2 \mathrm{Mb}$ to illustrate 2 copy gene dosage signals compared to control DNA in adjacent genomic regions. Predicted genes are not included. [Color figure can be viewed in the online issue, which is available at wileyonlinelibrary.com]

novo. We confirmed the deletion with a separate oligonucleotide based Agilent $244 \mathrm{~K}$ chromosomal microarray to define the borders more precisely and to evaluate for dosage complexity within or surrounding the deletion. This array study revealed a $555 \mathrm{~kb}$ loss on chromosome 16, at 16p13.3 (chr16:2,716,773-3,271,348; NCBI36/hg18 assembly) (Fig. 2) without evidence of associated gene dosage complexity (flanking or internal 2 or 3 copy segments).
The deleted segment involves 25 known genes. The deletion does not overlap with $C R E B B P$, the gene associated with RubinsteinTaybi syndrome. There are no reported CNVs that span the entire genomic segment of the deletion. However, subsegments of this region vary in the normal population in terms of copy number (Fig. 3), including chr16:2476823-2810537 (CNV3988) involving the SRRM2, TCEB, and PRSS33 for which both loss and gain in

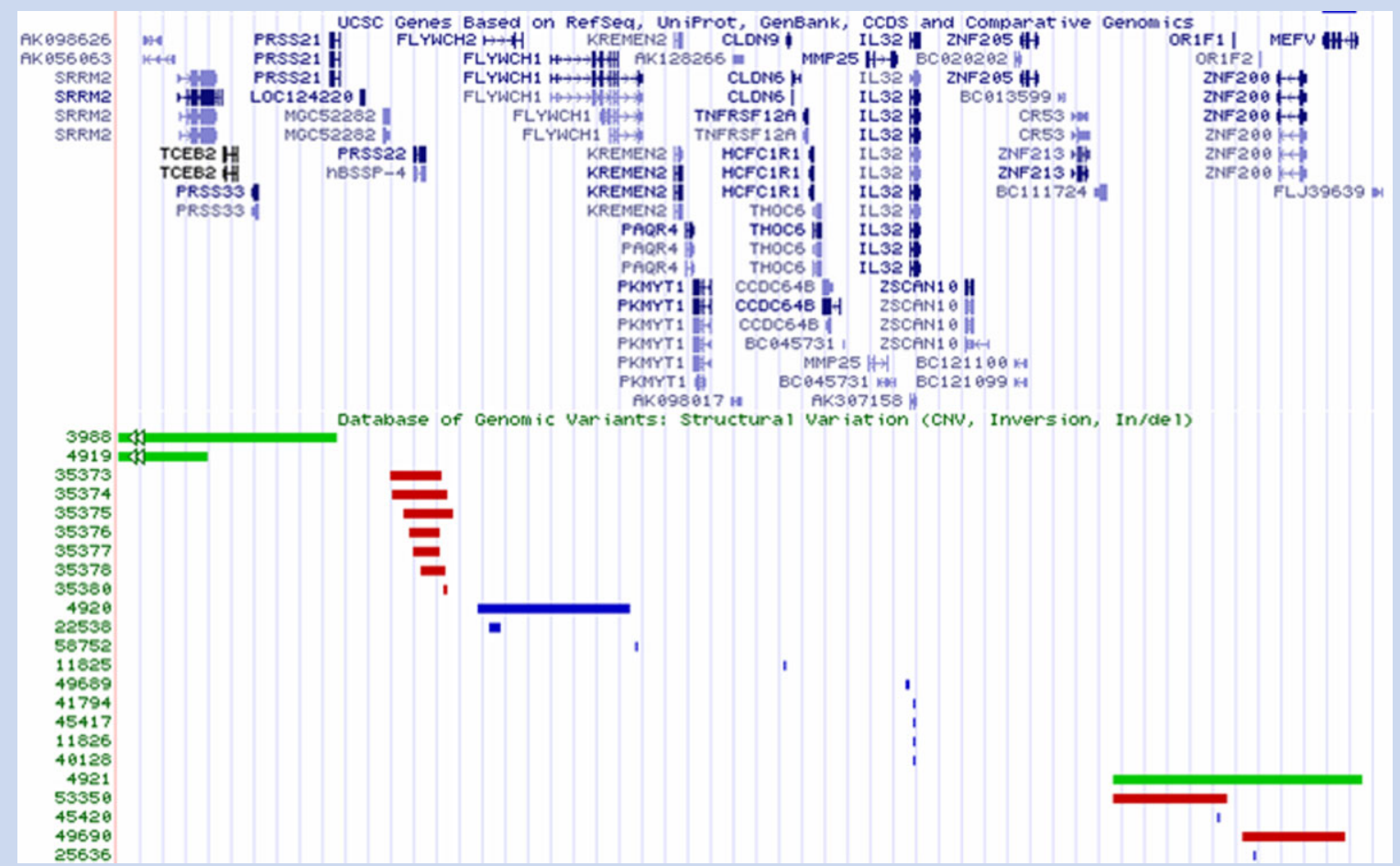

FIG. 3. Copy number variants (Database of Genomic Variants) in the 16p13.3 deleted region of the proband displayed beneath UCSC and RefSeq genes. Green bars are regions in which both gains and losses have been described; red bars are gains; and blue bars are losses. Variation numbers are displayed on the left in green. [Color figure can be viewed in the online issue, which is available at wileyonlinelibrary.com] 
TABLE I. Known Genes Within the Deleted Interval Are Given; Predicted ORFs or Predicted Genes Are Not Included

$\begin{array}{ll}\text { Gene } & \text { Description } \\ \text { SRRM2 } & \text { Splicing coactivator subunit SRm300 } \\ \text { TCEB2 } & \text { Elongin B isoform b } \\ \text { PRSS33 } & \text { Serine protease 33 } \\ \text { PRSS21 } & \text { Testisin isoform 3 } \\ \text { PRSS22 } & \text { Serine protease 22 } \\ \text { hBSSP-4 } & \text { Brain-specific protease 4 } \\ \text { FLYWCH2 } & \text { FLYWCH family member 2 } \\ \text { FLYWCH1 } & \text { FLYWCH-type zinc finger 1 isoform b } \\ \text { KREMEN2 } & \text { Kringle-containing transmembrane protein 2 } \\ \text { PAQR4 } & \text { Progestin and adipoQ receptor family member IV } \\ \text { PKMYT1 } & \text { Protein kinase Myt1 isoform 2 } \\ \text { CLDN9 } & \text { Claudin 9 } \\ \text { CLDN6 } & \text { Claudin 6 } \\ \text { TNFRSF12A } & \text { Tumor necrosis factor receptor superfamily } \\ \text { HCFC1R1 } & \text { Host cell factor C1 regulator 1 (XP01 dependent) } \\ \text { THOC6 } & \text { THO complex subunit 6 homolog } \\ & \text { (WD repeat-containing protein 58) } \\ \text { CCDC64B } & \text { Coiled-coil domain containing 64B } \\ \text { MMP25 } & \text { Matrix metalloproteinase 25 preproprotein } \\ \text { IL32 } & \text { Interleukin 32, isoform A } \\ \text { ZSCAN10 } & \text { Zinc finger and SCAN domain containing 10 } \\ \text { ZNF205 } & \text { Zinc finger protein 205 } \\ \text { CR53 } & \text { Putative transcription factor CR53 (CR53) } \\ \text { ZNF213 } & \text { Zinc finger protein 213 } \\ \text { ZNF200 } & \text { Zinc finger protein 200, isoform 2 } \\ \text { MEFV } & \text { Pyrin; Mediterranean fever protein } \\ \text { Blue 0utline Illustrates 18 Genes Not Located Within cNvs. }\end{array}$

copy number have been observed; chr16:2834323-2860376 (CNV35374) for which only gain in copy number involving only the PRSS22 and hBSSP4 genes has been observed; chr16:28710582935707 (CNV4920) involving all of FLYWCH2 and part of the FLYWCH1 gene for which loss has been observed; and chr16:3142783-3249414 (CNV4921) for which both loss and gain involving MEFV and ZNF200 has been observed. The remaining genes (18 in total) deleted in our patient for which no CNV has been described so far are highlighted in blue in Table I. These 18 genes, ignoring for the moment the potential for aberrant regulation of genes adjacent to the deletion, are the minimal list of candidates whose gene dosage is critical for development and cognitive function.

\section{DISCUSSION}

We describe a boy with a de novo deletion of $555 \mathrm{~kb}$ of $16 \mathrm{p} 13.3$ telomeric to CREBBP. Key features include tracheobronchomalacia, CT-proven metopic craniosynostosis, glandular hypospadias and chordee, torticollis, esotropia, strabismus, fifth finger clinodactyly, hallux valgus, and global developmental delay.

Isolated deletions of chromosome 16p13.3 are rare. The most commonly described genetic disorder in this region is RTS, which is an autosomal dominant disorder characterized by developmental delay and microcephaly, limb findings, and typical facial features [Hennekam et al., 1993]. Our patient demonstrates several features that are not consistent with RTS, including trigonocephaly secondary to metopic synostosis, normal head circumference, height and weight, normal thumbs and great toes, hypospadias, tracheobronchomalacia, and esotropia. The only reported overlapping deletion in the literature is that of Patient 2 of Bartsch et al. [1999], who sustained a large deletion of $16 \mathrm{p} 13.3$ totaling $\sim 2.7 \mathrm{Mb}$ on the telomeric side of CREBBP, including apparent loss of SRRM2. Unfortunately, it is difficult to make a direct comparison with our patient when there is such a significant additional loss of genetic material centromeric to the CREBBP gene in that patient. Also the Bartsch et al. patient expired at 7 months of age of severe RTS and pneumonia, pneumothorax and apparent multiple organ failure [Bartsch et al., 1999]; thus, comparison is hampered by lack of further development of Patient 2. That patient and ours had hypospadias, an uncommon finding in RTS. Patient 2 also had microcephaly, not uncommon in RTS, but there was no mention of metopic craniosynostosis. Unlike Patient 2, however, our patient did not experience seizures or life-threatening infections, which suggests that the features of severe RTS may be due to deletion of material more centromeric to that described for our patient. Altogether, the features of our patient seem distinct, other than the global developmental delay common with RTS.

Metopic craniosynostosis is a relatively rare form of craniosynostosis, which can occur in syndromic or non-syndromic forms. In fact, $50-58 \%$ of simple craniosynostosis are sagittal, $20-29 \%$ are coronal, $4-10 \%$ are metopic, and $2-4 \%$ involve the lambdoid suture [Cohen, 1979]. The metopic suture separates the frontal bones, therefore premature fusion leads to trigonocephaly. The metopic suture is normally the first suture to close, beginning in the third year of life.

Jehee et al. [2005] examined 76 unrelated patients (40 nonsyndromic patients and 36 syndromic). Their analysis included testing for microdeletions on chromosome 9 (monosomy 9 syndrome) and chromosome 11 (Jacobsen syndrome), two regions that have been shown to be associated with trigonocephaly. Approximately $20 \%$ of the syndromic patients demonstrated one of these deletions, while none of the non-syndromic patients were found to have a deletion. The potential contribution of a gene or genes in the region of the deletion on 16p13.3 in our patient will need to be assessed in future patients with syndromic or isolated forms of metopic craniosynostosis.

To evaluate the known contribution of genes in the deleted region to Mendelian diseases as well as the potential impact of haploinsufficiency to disease or risk we examined the deleted chromosomal region described in our patient for genes and copy number variants (CNVs). This region of $16 \mathrm{p} 13.3$ contains 25 documented RefSeq genes (hg18) as well as additional numerous uncharacterized loci or predicted genes. To date there have been no reported associations between haploinsufficiency for any of these genes and the clinical features of the patient. Several genes within the region deserve brief mention. One, $M E F V$, mutations of which cause autosomal recessive familial Mediterranean fever, is notable in that heterozygous mutation carriers are usually disease free, and at least one CNV loss has been observed in a healthy control population involving $M E F V$ (Fig. 3). The patient also has only one 
copy of TCEB2, which encodes Elongin B. Elongin B interacts with VHL, the gene product of the von Hippel Lindau gene, along with Elongin C, Cul 2, and Rbx 1 [Duan et al., 1995; Kishida et al., 1995; Lonergan et al., 1998; Kamura et al., 1999]. TCEB2 is contained within a described region of copy number variation (CNV3988) [Redon et al., 2006] for which both gains and losses have been identified among 270 HapMap control samples (Fig. 3). There is no current evidence that heterozygous loss of Elongin B increases risk for VHL related or other tumors. The PRSS21 gene also lies in the deleted region. PRSS21 encodes the protein Testisin, which is expressed exclusively in the testis and exhibits loss of expression in testicular tumors [Hooper et al., 1999]. Al-Jehani et al. [1995] found an association between loss of heterozygosity on chromosome $16 \mathrm{p}$ and testicular germ cell tumors suggesting that testisin may be a tumor suppressor, and Manton et al. [2005] showed that expression of testisin in testicular cancer cells in vitro reduced anchorage dependent cell growth as well as tumor development in the SCID mouse model. However, it is unknown whether constitutional heterozygous loss is associated with any increase in risk for testicular or any other cancer. Finally, the patient is deleted for one copy of KREMEN2. KREMEN2 is a transmembrane protein that binds in a ternary complex as a coreceptor for the WNT antagonist DKK1 to reduce WNT signaling. There is no abnormal phenotype to heterozygous or even homozygous loss of function of Kremen1 or Kremen 2 alone in mice, however, double mutant Kremen $1^{-1-} ;$ Kremen $^{-1-}$ mice demonstrate increased bone mass and polydactyly. WNT signaling is important for many developmental processes including cranial suture closure as studied in the mouse [Behr et al., in press], where inhibition of canonical WNT signaling promotes sagittal suture closure in mice. However, increased canonical WNT signaling, as might be expected for loss of KREMEN2 activity, indicates that the contribution of heterozygous KREMEN2 loss in our patient is unclear.

Examination of the CNV database (Database of Genomic Variants) shows that control chromosomes exhibit gains and/or losses of subsegments of the $555 \mathrm{~kb}$ deleted region in the patient (Fig. 3). While effects due to deletion of regulatory elements for genes outside of the deletion or proximity effects created by apposition of new sequences normally $555 \mathrm{~kb}$ apart could explain the clinical problems in our patient, our hypothesis is that haploinsufficiency for one or more of the remaining genes not within these small CNVs are most likely responsible for the malformations in the propositus. We acknowledge the inherent limitations when associating any new genetic mutation with physical characteristics or dysmorphic findings. It is true that new mutations occur with each successive generation, and the precise phenotypic effect of these mutations is often difficult to establish. Another factor to consider is that deletions may sometimes unmask recessive mutations on the non-deleted chromosomal homolog.

Therefore, caution must be used when attributing all of the physical characteristics noted in the proband to this specific deletion. It is our hope that a thorough clinical description of a patient with this genetic pattern would serve as a starting point to unlock any possible linkage of this area to expected phenotypic findings. Certainly, additional reports of similar or overlapping deletion patients would help to support or refute the hypothesis that some of this patient's dysmorphology is related to the changes at this genetic location. This hypothesis might also be tested by appropriate functional studies in mice or other model systems.

\section{ACKNOWLEDGMENTS}

The authors wish to thank the patient and his family for their support of this study.

\section{REFERENCES}

Al-Jehani RMA, Povey S, Delhanty JDA, Parrington JM. 1995. Loss of heterozygosity on chromosome arms $5 \mathrm{q}, 11 \mathrm{p}, 11 \mathrm{q}, 13 \mathrm{q}$, and $16 \mathrm{p}$ in human testicular germ cell tumors. Genes Chromosomes Cancer 13: 249-256.

Baldwin EL, Lee JY, Blake DM, Bunke BP, Alexander CR, Kogan AL, Ledbetter DH, Martin CH. 2008. Enhanced detection of clinically relevant genomic imbalances using a targeted plus whole genome oligonucleotide microarray. Genet Med 10:415-429.

Bartsch O, Rasi S, Delicado A, Dyack S, Neumann LM, Seemanova E, Volleth M, Haaf T, Kalscheuer V. 2006. Evidence for a new contiguous gene syndrome, the chromosome 16p13.3 deletion syndrome alias severe Rubinstein-Taybi syndrome. Hum Genet 120:179-186.

Bartsch O, Wagner A, Hinkel GK, Krebs P, Stumm M, Schmalenberger B, Böhm S, Balci S, Majewski F. 1999. FISH studies in 45 patients with Rubinstein-Taybi syndrome: deletions associated with polysplenia, hypoplastic left heart and death in infancy. Eur J Hum Genet 7:748-756.

Behr B, Longaker MT, Quarto N. 2010. Differential activation of canonical Wnt signaling determines cranial sutures fate: A novel mechanism for sagittal suture craniosynostosis. Dev Biol 344:922-940.

Cohen MM Jr. 1979. Craniosynostosis and syndromes with craniosynostosis: incidence, genetics, penetrance, variability and new syndrome updating. Birth Defects Orig Artic Ser 15:13-63.

Duan DR, Pause A, Burgess WH, Aso T, Chen DY, Garrett KP, Conaway RC, Conaway JW, Linehan WM, Klausner RD. 1995. Inhibition of transcription elongation by the VHL tumor suppressor protein. Science 269:1402-1406.

Hennekam R, Tilanus M, Hamel B, Voshart-van Heeren H, Mariman E, van Beersum S, van den Boogaard M, Breuning M. 1993. Deletion at chromosome $16 \mathrm{p} 13.3$ as a cause of Rubinstein-Taybi syndrome: clinical aspects. Am J Hum Genet 52:255-262.

Hooper JD, Nicol DL, Dickinson JL, Eyre HJ, Scarman AL, Normyle JF, Stuttgen MA, Douglas ML, Loveland KAL, Sutherland GR, Antalis TM. 1999. Testisin, a new human serine proteinase expressed by premeiotic testicular germ cells and lost in testicular germ cell tumors. Cancer Res 59:3199-3205.

Jehee FS, Johnson D, Alonso LG, Cavalcanti DP, de sa Moreira E, Alberto FL, Kok F, Kim C, Wall SA, Jabs EW, Boyadjiev SA, Wilkie AO, PassosBueno MR. 2005. Molecular screening for microdeletions at 9p22-p24 and $11 \mathrm{q} 23-\mathrm{q} 24$ in a large cohort of patients with trigonocephaly. Clin Genet 67:503-510.

Kamura T, Koepp DM, Conrad MN, Skowyra D, Moreland RJ, Iliopoulos O, Lane WS, Kaelin WG Jr., Elledge SJ, Conaway RC, Harper JW, Conaway JW. 1999. Rbx1, a component of the VHL tumor suppressor complex and SCF ubiquitin ligase. Science 284:657-661.

Kishida T, Stackhouse TM, Chen F, Lerman MI, Zbar B. 1995. Cellular proteins that bind the von Hippel-Lindau disease gene product: mapping of binding domains and the effect of missense mutations. Cancer Res 55:4544-4548.

Lonergan KM, Iliopoulos O, Ohh M, Kamura T, Conaway RC, Conaway JW, Kaelin WG Jr. 1998. Regulation of hypoxia-inducible mRNAs by the 
von Hippel-Lindau tumor suppressor protein requires binding to complexes containing elongins $\mathrm{B} / \mathrm{C}$ and $\mathrm{Cul2}$. Mol Cell Biol 18: $732-741$

Manton KJ, Douglas ML, Netzel-Arnett S, Fitzpatrick DR, Nicol DL, Boyd AW, Clements JA, Antalis TM. 2005. Hypermethylation of the 5' CpG island of the gene encoding the serine protease Testisin promotes its loss in testicular tumorigenesis. Br J Cancer 92:760-769.

Redon R, Ishikawa S, Fitch KR, Feuk L, Perry GH, Andrews TD, Fiegler H, Shapero MH, Carson AR, Chen W, Cho EK, Dallaire S, Freeman JL, González JR, Gratacòs M, Huang J, Kalaitzopoulos D, Komura D,
MacDonald JR, Marshall CR, Mei R, Montgomery L, Nishimura K, Okamura K, Shen F, Somerville MJ, Tchinda J, Valsesia A, Woodwark C, Yang F, Zhang J, Zerjal T, Zhang J, Armengol L, Conrad DF, Estivill X, Tyler-Smith C, Carter NP, Aburatani H, Lee C, Jones KW, Scherer SW, Hurles ME. 2006. Global variation in copy number in the human genome. Nature 444:444-454.

Wójcik C, Volz K, Ranola M, Kitch K, Karim T, O’Neil J, Smith J, TorresMartinez W. 2010. Rubinstein-Taybi syndrome associated with Chiari type I malformation caused by a large $16 \mathrm{p} 13.3$ microdeletion: a contiguous gene syndrome? Am J Med Genet Part A 152A:479-483. 